\title{
Multiple Micronutrients Versus Iron Folic Acid on Pica and Hemoglobin Levels Among Pregnant Women in Kenya
}

\author{
Betsy Chebet Rono ${ }^{1}$, Yeri Kombe ${ }^{2}$, Anselimo Makokha ${ }^{3}$ \\ ${ }^{1}$ Department of Public Health, School of Public Health, Jomo Kenyatta University of Agriculture and Technology, Nairobi, Kenya \\ ${ }^{2}$ Center for Public Health Research, Kenya Medical Research Institute, Nairobi, Kenya \\ ${ }^{3}$ Department of Food Science and Technology, Jomo Kenyatta University of Agriculture and Technology, Nairobi, Kenya
}

Email address:

bcheriro@jkuat.ac.ke (B. C. Rono)

\section{To cite this article:}

Betsy Chebet Rono, Yeri Kombe, Anselimo Makokha. Multiple Micronutrients Versus Iron Folic Acid on Pica and Hemoglobin Levels Among Pregnant Women in Kenya. Central African Journal of Public Health. Vol. 4, No. 4, 2018, pp. 95-101.

doi: 10.11648/j.cajph.20180404.11

Received: July 6, 2018; Accepted: July 25, 2018; Published: August 27, 2018

\begin{abstract}
Pica is an indicator of low micronutrients in a pregnant woman's health. Low micronutrients pose a great risk to an otherwise healthy pregnancy. A healthy pregnancy, results in a healthy mother and baby; the critical probability in every pregnancy. The aim of the study was to introduce multiple micronutrients to promote maternal nutrition and influence development in pregnancy health outcomes. Sub-populations at risk of nutritional deficiencies and provided opportunities for early intervention to support the known benefit of multiple micronutrients on pregnancy outcomes i.e. up to six weeks (42 days) post delivery. The variations on pregnancy health, pica and hemoglobin levels among the Multiple Micronutrients (MMs) and Iron Folic Acid (IFA) groups. This was a block randomized controlled study. The intervention arm received MMs while the control received the usual care of IFA. A structured questionnaire with open and closed ended questions was used. Focus group discussions were conducted using a semi-structured guide to collect the qualitative data on the effects of prenatal multiple micronutrients among the pregnant women. The study assumed equal variances based on the Levene's test of $>0.10$ (f, $0.196, \mathrm{p}=0.661)$. The difference in inter trimester weight gain means was $5.85 \mathrm{kgs}$ for MMs and $5.52 \mathrm{kgs}$ for IFA (t, 0.109 , $\mathrm{p}=0.914$ ), duration to resumption of household work was 7 days for MMs and 14 days for the IFA groups. The hemoglobin level increased by; $1.25 \mathrm{~g} / \mathrm{dl}$ for MMs, and $0.45 \mathrm{~g} / \mathrm{dl}$ for the IFA ( $\mathrm{t}, 0.897, \mathrm{p}=0.376$ ). Pica for stones was experienced among $55.6 \%$ of pregnant women; however there was no pica within 14 days among MMs enrollment, but persisted in the IFA group. The study demonstrated no significance in the importance of multiple micronutrients in increasing hemoglobin level $(\mathrm{P}, 0.376)$, reduction of pica craving during pregnancy $(\mathrm{P}, 0.176)$ and resumption of household duties $(\mathrm{P}, 0.067)$ post delivery compared to those on Iron Folic Acid.
\end{abstract}

Keywords: Nutrients Deficiencies, Pregnancy Outcomes, Weight Gain, Return to Work

\section{Introduction}

According to past studies, pica status is a preliminary clinical indicator for micronutrient deficiency. [1] Nutrition and mineral deficiency precipitates pica behavior which can either be: geoghagia, pagophagia or amylophagia. Nutritional advice and prescriptions for multivitamins are given but never obtained leading to continued pica behavior. [1]

The causal relationship between pica and micronutrients remains unclear needing further studies. This then necessitates investigation into the strength of association which has been inconsistent. Iron and zinc supplementation has been associated with cessation of pica. Pica is common regardless of sex, race, culture, social position or residence. [2]

Despite all the studies, pica etiology remains unclear with a prevalence of between $0.02-74 \%$ in Iran and $46 \%$ among the pregnant adolescents in the USA. The relationship between pica and iron status biomarkers is unknown though it has been in observance since $>2000$ years according to Hippocrates in 400BCE. [3] Pica practice is common in developing countries. Pica prevalence in Ghana is $9.1 \%$, in Pemba, Tanzania for amylophagia $-36.3 \%$, geophagia and 
any pica- $40.1 \%$. Amylophagia has been observed to be associated with low hemoglobin concentration and iron deficiency anemia. [4]

Women practicing pica have a 1.23 times more likely to be anemic compared to those who didn't. Anemia affects 38\% of pregnant women globally. [5] Anemia prevalence in Africa is $44.6 \%$ : Ghana is 56\%; and Uganda $32.5 \%$. [5] According to World Health Organization, anemia prevalence is high and unacceptable public Health concern. [6]

According to WHO classification of anemia; hemoglobin level $<11.0 \mathrm{~g} / \mathrm{dl}$ among the pregnant women is anemia, [1] and has a higher risk of preterm birth, low birth weight and small for gestational weight. Low hemoglobin in third trimester has a higher risk of low birth weight. [7, 8]

According to past studies, anemia is common among women from developing countries and related to iron deficiency and low intake. Iron deficiency can be prevented through supplementation to prevent onward complications to their children in future. [9]

\section{Method}

\subsection{Ethical Considerations}

The study was implemented after ethical consideration and approval was sought from the Moi University/Moi Teaching and Referral Hospital Institutional Research and Ethics Committee (IREC) and approval of the study topic by the Board of Postgraduate Studies of Jomo Kenyatta University of Agriculture and Technology (JKUAT). Permission to implement the study within the Tea Estates was sought from the Chief Executive Officer of the entire Eastern Produce Tea Estates, then the Doctor in charge of the Nandi Hills Doctors Scheme Association. Eastern Produce Tea Estates is housed within the Nandi County in Kenya.

\subsection{Study Design}

This sub-study was part of a block randomized controlled study. The Tea Estates administrative blocks were adopted and randomized to either the treatment or control arms. All pregnant women within the treatment and control arm blocks, meeting the inclusion criteria, were enrolled in the community until the sample size was achieved.

\subsection{Study Participants}

Participants were enrolled from the fourth month of pregnancy and followed up till forty two days post delivery. Community entry was done by seeking permission from the estate manager, clinical officer and village headman. The village field educator escorted the researcher to the respective homes with pregnant women for study enrollment. Study participants from the treatment arm were administered with a fifteen micronutrients capsule daily with meals, while the control arm continued with the usual standard care of taking Iron folic acid.

\subsection{Study Implementation}

Enrollment was conducted within the village homes of the women. Thereafter, bimonthly visits were done to the homes within the first month; thereafter next visits were conducted, during the third trimester, a week within delivery and at forty two days post delivery. Data was collected on pregnancy health i.e. age, parity, level of education, gestation, hemoglobin level, occupation, sickness and pica cravings.

\subsection{Statistical Analysis}

Data analysis followed four key steps: first the study sought to identify any possible relations between confounding factors and short term maternal neonatal outcomes in bivariate analysis; secondly, bivariate analysis was conducted between multiple micronutrients and iron folic acid on pica practice frequency and duration; thirdly bivariate analysis was conducted between multiple micronutrients and iron folic acid on hemoglobin levels; finally independent $t$ test was conducted between the multiple micronutrients and iron folic acid groups respectively to compare the means for any significance.

Qualitative data was collected during the focus group discussions: one was conducted in the control and intervention clusters respectively. The data was collected using hand written notes and a voice recorder. Thereafter, the information in the voice recorder was transcribed and checked word per word to ensure no information was left out. The hand written notes from the two focus groups was compared with the transcribed information to ensure no detail was omitted. Thematic analysis was conducted to derive common themes in using multiple micronutrients versus iron folic acid between the groups. Qualitative variables derived from the questionnaires were expressed as percentages.

Descriptive and inferential statistics was applied to quantitative variables. Descriptive statistics was undertaken on the demographic data i.e. age, occupation, marital status, education level and antenatal visits frequency. Data was analyzed and presented in tables and graphs.

Inferential statistics was applied by calculating the Levene's test of equal variance assumption and through the independent t-test to establish whether the difference in means being observed is by chance alone or as a result of the multiple micronutrients or Iron folic acid on the pica and hemoglobin's variable tests.

Bivariate analysis was applied to establish the association between multiple micronutrients; pica and hemoglobin. Multivariate analysis was also conducted to establish association between multiple micronutrients; pica and hemoglobin while adjusting for any possible confounding variables. All statistical analysis results with $\mathrm{P}<0.05$ were considered significant. All analyses were done using SPSS version 16 .

\section{Results}

Sixty study participants: out of one hundred and twenty 
five pregnant women; met the inclusion criteria and were included in the study. The main reasons for ineligibility were that their pregnancy was less than four months, had twin pregnancy or had less than two weeks to expected delivery date; in compliance to the specified eligibility criteria.

Maternal mean age was twenty five (25.65) years; with the youngest woman being fifteen years (15) and eldest during the pregnancy experience was thirty eight (38) years correspondingly with a standard deviation of $+/-6.01$ years. Seventy five percent (45) of the women were married with only $25 \%$ (15) single (See table 2 ).

Average parity was 1.24 children with majority of the women being pregnant for the first time with a parity of 0.00 at $46 \%$ and highest having a parity of 6.00 with a standard deviation of $+/-1.48$. Average number of children per woman was 2.03 with the least having no children and highest having at most six (6) children (See table 1).

The pregnant women had varied education levels: primary $61.7 \%$ (37), secondary 35\% (21) and only $3.3 \%$ (2) had tertiary education. Thirty nine out of sixty women were working: $58.3 \%$ (35) were tea pluckers; $6.7 \%$ (4) factory workers; 30\% (18) were housewives; 3.3\% (2) were students in primary and secondary schools respectively; and $1.7 \%$ (1) was a teacher correspondingly. The pregnant women who were tea pluckers were able to pluck and average of 24.9kilograms daily; with the least having no plucking at all and the highest having sixty kilograms of tea plucked daily with a standard deviation of $+/-13.75$ kilograms daily. They were able to work for an average of 7.9 hour s daily not working at all and the highest working for ten hours daily with a standard deviation of $+/-2.26$ hours. Adolescent pregnancies were experienced at $18.3 \%$ (11) but the eldest women being between 35-39 years at 10\% (6). Majority of the women were between 20-24 years at $31.7 \%$ (19) correspondingly (See table 2).

Pica for stones was $73.3 \%$ (44), charcoal $15.0 \%$ (9), gas $1.7 \%$ (1) and other products- starch aroma $10 \%$ (6). However, there was preference for assorted kinds of food i.e. carbohydrates, proteins, fruits and vegetables: most preferred fruits at $31.7 \%$ (19); carbohydrates at $16.7 \%$ (10); least preferred was other vegetables (kales, pumpkin) at 3.3\% (2) and milk at $3.3 \%$ (2) correspondingly. There was no difference in pica experience between the treatment and control arm at study enrollment $(\mathrm{P}=0.217)$. However, after at least two weeks of being administered and using multiple micronutrients and Iron folic acid respectively: the MMs group had pica at $6 \%$ (2) and IFA at 90\% (27) correspondingly.

This is also consistent with the focus group discussions with the groups:

A woman said "Since I became pregnant, I have been eating stones and have to carry them in my bag because when I am not doing some work I throw some in my mouth to keep the urge down”. Woman \# 5 in Control group.

Table 1. Showing Women's Demographics Ref: Betsy original 12018.

\begin{tabular}{|c|c|c|c|c|}
\hline Mother characteristics & Specific characteristic & & Study cohort & Percentage \% \\
\hline \multirow{5}{*}{ Age in years } & Mean & 25.65 & \multirow{5}{*}{60} & \multirow{5}{*}{100} \\
\hline & Median & 25 & & \\
\hline & $95 \%$ CI Age range - Minimum & 15 & & \\
\hline & -Maximum & 38 & & \\
\hline & Std. deviation & $+/-6.01$ & & \\
\hline \multirow{5}{*}{ Parity } & Mean & 1.24 & \multirow{5}{*}{60} & \multirow{5}{*}{100} \\
\hline & Median & 1.00 & & \\
\hline & $95 \%$ CI Age range - Minimum & 0.00 & & \\
\hline & Maximum & 6.00 & & \\
\hline & Std. deviation & $+/-1.48$ & & \\
\hline \multirow{4}{*}{ No. of children } & Mean & 2.03 & \multirow{4}{*}{60} & \multirow{4}{*}{100} \\
\hline & Median & 2.00 & & \\
\hline & $95 \%$ CI Age range - Minimum & 0.00 & & \\
\hline & Maximum & 6.00 & & \\
\hline \multirow{5}{*}{ No. tea kilos plucked in kgs } & Mean & 24.9 & \multirow{5}{*}{30} & \multirow{5}{*}{58} \\
\hline & Median & 25.00 & & \\
\hline & $95 \%$ CI Age range - Minimum & 0.00 & & \\
\hline & Maximum & 60.00 & & \\
\hline & Std. deviation & $+/-13.75$ & & \\
\hline \multirow{5}{*}{ Hours worked in hours } & Mean & 7.9 & \multirow{5}{*}{39} & \multirow{5}{*}{65} \\
\hline & Median & 8.0 & & \\
\hline & 95\% CI Age range - Minimum & 0.00 & & \\
\hline & Maximum & 10.00 & & \\
\hline & Std. deviation & $+/-2.26$ & & \\
\hline \multirow[t]{5}{*}{ Hemoglobin levels - } & Mean & 11.39 & \multirow[t]{5}{*}{60} & \multirow[t]{5}{*}{100} \\
\hline & Median & 11.20 & & \\
\hline & $95 \%$ CI Age range - Minimum & 7.40 & & \\
\hline & Maximum & 15.20 & & \\
\hline & Std. deviation & $+/-1.46$ & & \\
\hline
\end{tabular}

But a woman in the MMS - intervention group said "I had tendencies to eat soil and stones when I became pregnant: but after taking the vitamins for two weeks; I didn't have the urge to eat them again, I forgot that I used to eat them!" Woman \#3 in the intervention (MMs) group 
Table 2. Demographic characteristics'frequencies in MMs versus IFAs groups.

\begin{tabular}{|c|c|c|c|c|}
\hline \multirow{2}{*}{ Characteristic } & Frequency & Percentage $\%$ & Frequency & Percentage $\%$ \\
\hline & \multicolumn{2}{|l|}{ MMs } & \multicolumn{2}{|l|}{ IFAs } \\
\hline Parity- 0 & 11 & 36.7 & 16 & 55.6 \\
\hline 1 & 9 & 30.0 & 0 & 0 \\
\hline 2 & 4 & 13.3 & 12 & 38.8 \\
\hline 3 & 0 & 0 & 2 & 5.6 \\
\hline 4 & 2 & 6.7 & 0 & 0 \\
\hline 5 & 2 & 6.7 & 0 & 0 \\
\hline 6 & 2 & 6.7 & 0 & 0 \\
\hline Total & 30 & $100 \%$ & 30 & $100 \%$ \\
\hline Occupation - Business & 3 & 10 & 1 & 3.3 \\
\hline Factory worker & 3 & 10 & 2 & 6.7 \\
\hline Housewife & 7 & 23.4 & 11 & 36.7 \\
\hline Tea plucker & 15 & 50 & 15 & 50 \\
\hline Students & 1 & 3.3 & 1 & 3.3 \\
\hline Teacher & 1 & 3.3 & 0 & 0 \\
\hline Total & 30 & $100 \%$ & 30 & $100 \%$ \\
\hline Level of education -Primary & 20 & 61 & 17 & 56.7 \\
\hline Secondary & 9 & 35 & 12 & 40.0 \\
\hline Tertiary & 1 & 3.3 & 1 & 3.3 \\
\hline Total & 30 & $100 \%$ & 30 & $100 \%$ \\
\hline Marital status - Married & 21 & 83.3 & 24 & 80.0 \\
\hline Single & 9 & 16.7 & 6 & 20.0 \\
\hline Total & 30 & $100 \%$ & 30 & $100 \%$ \\
\hline Maternal age - $15-19$ years & 8 & 27.8 & 3 & 10 \\
\hline 20-24 years & 10 & 33.3 & 9 & 30 \\
\hline $25-29$ years & 7 & 23.3 & 7 & 23.3 \\
\hline $30-34$ years & 2 & 6.7 & 8 & 26.7 \\
\hline $35-39$ years & 3 & 10 & 3 & 10 \\
\hline Total & 30 & $100 \%$ & 30 & $100 \%$ \\
\hline Foods preferred - Fruits-mangoes, pineapples, avocado, quava & 12 & 40 & 7 & 23.3 \\
\hline Carbohydrates - ugali, chapatti, porridge, potatoes, Chips & 3 & 10 & 7 & 23.3 \\
\hline Carbohydrates and beans & 5 & 16.7 & 4 & 13.3 \\
\hline Milk & 1 & 3.3 & 1 & 3.3 \\
\hline Proteins - Fish, liver, meat (matumbo) & 0 & 0 & 4 & 13.3 \\
\hline Indigenous vegetables-"nderema", spider flower, black night shade & 1 & 3.3 & 5 & 16.7 \\
\hline Other vegetables -kales, pumkins & 2 & 6.7 & 0 & 0 \\
\hline Snacks- soda, biscuits & 4 & 13.3 & 1 & 3.3 \\
\hline - None preferred- eats all & 2 & 6.7 & 1 & 3.3 \\
\hline Total & 30 & $100 \%$ & 30 & $100 \%$ \\
\hline Pica after two weeks - yes & 2 & 6 & 27 & 90 \\
\hline No & 28 & 94 & 3 & 10 \\
\hline Total & 30 & $100 \%$ & 30 & \\
\hline
\end{tabular}

Ref: Betsy original 22018

Average anemia prevalence as per the WHO classification i.e. hemoglobin $<11.0 \mathrm{~g} / \mathrm{dl}$ was $41.5 \%$ among the pregnant women with MMs group having an average of $43.75 \%$ and IFA group at $40 \%$ respectively.

Most women experience dizziness at $48 \%$ followed by nausea at $20 \%$ and vomiting at $18 \%$; though about $6 \%$ raised no complaint during their pregnancy experience. There was no association observed between sickness and pica practice; those sick at $8.3 \%(<5)$, but those not sick practiced pica at
$25 \%$ (15). There was no significant difference in sickness and pica experience between the treatment and control arms with a Chi-square significance at $(\mathrm{p}=0.217)$. There was difference observed between length of work duration and pica practice $(\mathrm{p}=0.000)$; longer working hours was associated with a higher number of women practicing pica, (See Figure 1 and Table 5 below). A minimal number of women were applied to test this variable; the association of work and pica practice versus those who regularly worked for longer hours only. 
Table 3. The t test for pica and hemoglobin levels at 58 degrees of freedom.

\begin{tabular}{|c|c|c|c|c|c|c|c|c|}
\hline \multirow{3}{*}{ Variables } & \multicolumn{2}{|c|}{$\begin{array}{l}\text { Levene's Test for } \\
\text { Equality of Variances }\end{array}$} & \multicolumn{6}{|c|}{ t-test of equality of means } \\
\hline & \multirow{2}{*}{$\mathbf{F}$} & \multirow{2}{*}{ Sig. } & \multirow{2}{*}{$\mathbf{t}$} & \multirow{2}{*}{ df } & \multirow{2}{*}{ Sig. 2-tailed } & \multirow{2}{*}{ Mean Difference } & \multicolumn{2}{|c|}{ 95\% Confidence Interval of the Difference } \\
\hline & & & & & & & Lower & Upper \\
\hline Pica & 2.096 & 0.000 & -2.150 & 58 & 0.037 & -0.615 & -1.192 & -0.038 \\
\hline HB levels in 2nd & 2.079 & 0.157 & 0.051 & 58 & 0.960 & 0.024 & -0.932 & 0.980 \\
\hline Change in HB levels & 0.196 & 0.661 & 0.897 & 58 & 0.376 & 0.796 & -1.005 & 2.5978 \\
\hline Weight added in 3rd & 0.308 & 0.582 & 0.109 & 58 & 0.914 & 0.331 & -5.806 & 6.467 \\
\hline Weight in 2nd trimester & 0.045 & 0.832 & 1.770 & 58 & 0.083 & 5.284 & -0.712 & 1.128 \\
\hline
\end{tabular}

Ref: Betsy Original 32018

There was a non- significant difference of $0.796 \mathrm{~g} / \mathrm{dl}$ increase in the hemoglobin levels of the MMs versus IFA with a $(\mathrm{t}, 0.897, \mathrm{p}=0.376$.). However, there was a significant difference on pica practice among the two groups with a $(\mathrm{t}=$ -2.150 at $58 \mathrm{df}, \mathrm{p}=0.037$ ). (See table 3 above). The pregnant women $(n=60)$ both groups i.e. MMs and IFAs; on enrollment, experienced varied complaints: Dizziness at $47 \%$, nausea at $20 \%$, vomiting at $18 \%$, fatigue at $2 \%$ and $5 \%$ had no complaints experienced.

\section{Bar Chart}

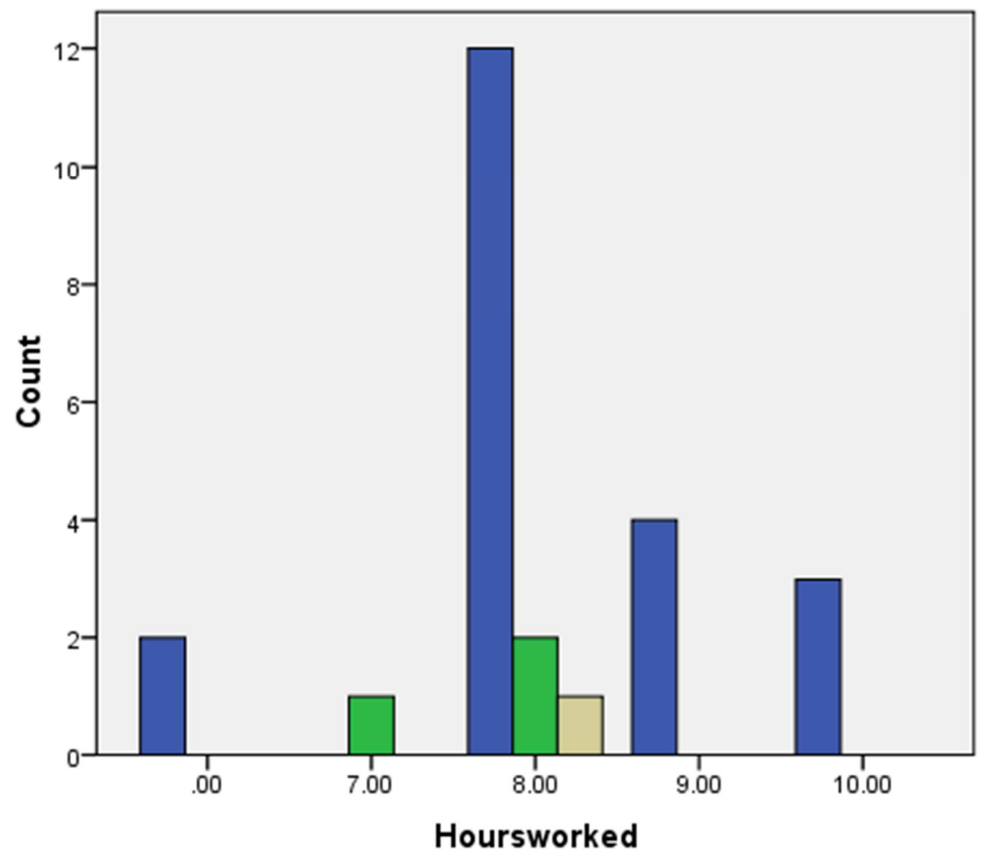

Ref: Betsy original 42018

Figure 1. Association between hours worked and pica types among the women.

Table 4. Test Statistics showing hemoglobin levels and pica.

\begin{tabular}{|c|c|c|c|c|c|c|}
\hline & & & Enrolled & HB levels in 2nd & Change in HB levels & Pica \\
\hline Chi-Square & & & $1.852^{\mathrm{a}}$ & $11.585^{\mathrm{b}}$ & $13.158^{\mathrm{c}}$ & $51.976^{\mathrm{d}}$ \\
\hline Df & & & 58 & 58 & 58 & 58 \\
\hline Asymp. Sig. & & & .174 & .996 & .983 & .000 \\
\hline \multirow{3}{*}{ Monte Carlo Sig. } & Sig. & & $.223^{\mathrm{e}}$ & $.998^{\mathrm{e}}$ & $.988^{\mathrm{e}}$ & $.000^{\mathrm{e}}$ \\
\hline & \multirow{2}{*}{$95 \%$ Confidence Interval } & Lower Bound & .213 & .997 & .985 & .000 \\
\hline & & Upper Bound & .234 & .999 & .991 & .000 \\
\hline
\end{tabular}

Ref: Betsy Original 52018

a. 0 cells $(.0 \%)$ have expected frequencies less than 5 .

b. 28 cells $(100.0 \%)$ have expected frequencies less than 5 . The minimum expected cell frequency is 1.5 .

c. 27 cells $(100.0 \%)$ have expected frequencies less than 5 . The minimum expected cell frequency is 1.4 .

There was a significant association between pica and hemoglobin levels. Women with minimal pica practice had no anemia, p, 0.000 (See table 4 above). Use of multiple micronutrients reduced the urge of pica practice. 
Table 5. Association between hours worked versus pica.

\begin{tabular}{|c|c|c|c|c|}
\hline & & & Hours worked & Pica \\
\hline Chi-Square & & & $26.000^{\mathrm{a}}$ & $29.120^{b}$ \\
\hline df & & & 58 & 58 \\
\hline Asymp. Sig. & & & .000 & .000 \\
\hline \multirow[t]{2}{*}{ Monte Carlo Sig. } & \multirow{2}{*}{$95 \%$ Confidence Interval } & Lower Bound & .000 & .000 \\
\hline & & Upper Bound & .049 & .049 \\
\hline
\end{tabular}

a. 28 cells $(100.0 \%)$ have expected frequencies less than 5 . The minimum expected cell frequency is 5.0 .

b. 0 cells $(.0 \%)$ have expected frequencies less than 5 . The minimum expected cell frequency is 8.3 .

c. Based on 60 sampled

\section{Discussion}

Fertility rate was 2.03 which is below the national fertility rate of 3.9 in 2014 down from 4.6 in 2008 \& 2009. [10], [11] The education attainment experience in this setting was at $38 \%$ for secondary level. This is below the national average which currently is placed at $43 \%$. Primary education level was at $37 \%$ which is higher than the national level average of 25\%. [11]

The average hemoglobin level experienced in this setting was $11.39 \mathrm{~g} / \mathrm{dl}$ which is above the World health Organization recommended non-anemic hemoglobin level of $11.0 \mathrm{~g} / \mathrm{dl}$. Hemoglobin level above $11.0 \mathrm{~g} / \mathrm{dl}$ is encouraged during pregnancy: to prevent adverse neonatal outcomes; prevent risk for preterm; low birth weight. Anemia prevalence among the pregnant is $57.1 \%$. [7], [12]

The anemia prevalence was $41.5 \%$ with the MMs arm having a prevalence of $43.75 \%$ versus the IFA arm having a prevalence of $40 \%$ respectively. The anemia prevalence is below the WHO recommended level; but consistent with the global anemia among the pregnant women which is $41.8 \%$; and also in the African region which has a prevalence of $44 \%$. Ghana has anemia prevalence of $56 \%$. Uganda has anemia prevalence of $32.5 \%$. [5], [13] Pica is believed to be a clinical indicator of micronutrient deficiency. The pica experience and practice among the pregnant women was diverse: pica for stone and clay i.e. geophagia was at $73.3 \%$, charcoal at $15 \%$. This is consistent with meta-analysis conducted which demonstrated a prevalence of between $11.0 \%-76.5 \%$. [1] This is further consistent with a study done in Iran which gave a range of $0.02 \%$ to $74 \%$. [2] Pica experience is experienced more among the pregnant adolescents in the USA at $46 \%$ with pagophagia (pica for ice) at $37 \%$. [3] Pica experience for geophagia (pica for soil) in Tanzania is at $5.2 \%$ and amylophagia (pica for raw starch) at $36.3 \%$ and other pica practices at $40 \%$. [4] Ghana pica practice prevalence is at $9.1 \%$. [5]

The study benefited from the administrative blocks within the Tea Estates which made it efficient in randomization of the study area to either the intervention or control blocks. The study experienced limitations in the design adopted in its implementation. The study would have achieved better results if the double blind randomized design would have been adopted. However, this was limited to finances required to repackage and import the multiple vitamins and combine the iron folic acid to one capsule same as Iron Folic Acid one tablet implemented earlier by the Ministry of Health.

\section{Conclusion}

Multiple micronutrients supplementation has a non significant effect on hemoglobin level increase but a significant effect on pica practice reduction and control. World Health Organization approved use of a fifteen micronutrients to promote pregnancy health: but there is no direct policy to promote and task the governments and Ministries of Health to enhance intake among the pregnant women. There is need for a WHO policy on multiple micronutrients use among the pregnant women with a focus on community initiatives. The Ministry of Health has only managed to implement the Iron and Folic Acid tablets being a two micronutrients supplement. However, the women are still experiencing poor pregnancy health outcomes. Use of the fifteen micronutrient capsule has proven efficient and easy to take supported by marked improvement in pica practice and hemoglobin levels improvement.

There is need to replace the current Iron Folic Acid package with the fifteen multiple micronutrients given to women during pregnancy to prevent pica for stones(soil and clay) eating which has promoted anemia by encouraging helminthes and other worms infestation.

There is need for more studies to support other benefits of multiple micronutrients i.e. pica practice suppression and hemoglobin levels increase; other than the focus on birth weight increase.

\section{References}

[1] Miao D, Young S L, Golden C D. A meta-analysis of pica and micronutrient status. American Journal of Human Biology 2015 January; 27(1): 84-93. Doi:10.1002/ajhb.22598

[2] Ezzedin N, Zavosly R, Noroozi M, Sarichloo M E, Jahanihashemi H. The association between postpartum Depression and Pica during pregnancy. Global Journal of Health Science; vol. 8, no. 4; 2016. ISSN 1916-9736. Doi: $10.5539 /$ gjhs.v8n4p120

[3] Lumish R A, Young S L, Looper E, Pressman E, Guillet R, O'Brien K O. Gestational Iron Deficiency is associated with Pica Behaviors in Adolescents. The Journal of Nutrition 144: 1533-1539; 2014. NCT01019902. Doi:10.3945/jn.114.192070. 
[4] Young S L, Khaitan S S, Farag T H, Kavie J A, Ali S M, Hajji H, Rasmussen K M, Pelto R J. Association of pica with anemia and gastrointestinal distress among pregnant women in Zanzibar, Tanzania. Am J. Trop. Medicine and Hygiene. 83(1), 2010, pp 144-151. Doi.10.4269/ajtmh 2010.09.0442

[5] WHO. The global prevalence of anemia in 2011. Geneva: World Health Organization: 2015.

[6] Ononge S, Campbell O, Mirembe F. Hemoglobin status and predictors of anemia among pregnant in Mpigi, Uganda. BMC Research Notes 2014, 7:712 http:// www.biomedcentral.com/1756-0500/7/712

[7] Sukrat B, Wilasrusmee C, Siribumrungwong B, McEnvoy M, Okaschroen C, Attia J, Thakkinstian A. Hemoglobin concentration and pregnancy outcomes: A systematic Review and meta-analysis. Biomed Research International vol. 2013 article Id 769057. http://dx.doi.org/10.1155/2013/769057

[8] Savajols E, Burguet A, Grimaldi M, Godoy F, Sogot P, Semama D S. Maternal Hemoglobin and short-term Neonatal outcome in preterm neonates. PLoS ONE 9(2):e89530. Doi:10.1371/journal.pone.0089530
[9] Pena-Rosas J B, De-Regil L M, Daswel T, Viteri F E. Intermittent oral iron supplementation during pregnancy (Review) Cochrane database system Review. Author manuscript: available in PMC 2014, June 13.

[10] Kenya National Bureau of Statistics. Kenya Demographic and Health Survey 2008-09 https://dhsprogram.com/pubs/pdf/fr229/fr229.pdf

[11] Kenya National Bureau of Statistics. Kenya Demographic and Health Survey 2014. https://dhsprogram.com/pubs/pdf/fr308/fr308.pdf

[12] Jwa SC, Fujiwara T, Yamanobe Y, Kozuka K, Sago H. Changes in maternity hemoglobin during pregnancy and birth outcomes. BMC Pregnancy and Childbirth (2015)15:80. Doi.10.1186/s12884-015-0516-1

[13] Intiful F D, Wiredu E K, Asare G A, Asante M, Adjei D N. Anemia in pregnant adolescent girls with malaria and practicing pica. Pan African Medical Journal 2016; Doi.10.11604/pamj.2016.24.96.9282 